\title{
Filling the News Hole? UK community news and the crisis in local journalism
}

Andy Williams (Cardiff University), Dave Harte (Birmingham City University), and Jerome Turner (Birmingham City University)

The public interest value of news is often viewed through the prism of its relationship to democracy (McNair 2009). Key to this is idea that representative democracy enables good government most effectively if citizens' decisions are based on accurate and reliable (and where necessary oppositional) information (Habermas 1989; Chambers and Costain 2001). McNair identifies four principal (and inter-related) democracy-enabling roles for the news. He sees news: as a source of accurate information for citizens; as a watchdog/fourth estate; as a mediator and/or representative of communities (a role which can help with community cohesion); and as an advocate of the public in campaigning terms (McNair 2009, 237-40). The value of local news has been defined similarly, as indicated by Franklin when he writes, 'local newspapers should offer independent and critical commentary on local issues, make local elites accountable, [and] provide a forum for the expression of local views on issues of community concern' (Franklin 2006a, xix).

However, numerous studies have found the on-going crisis in the UK news industry is endangering the 'local-ness', quality, and independence of local news (Fenton 2011; Franklin 2006b). These studies find that as revenues fall and staff are cut, workloads increase, mainstream local news relies more on official sources and PR, and that only a very narrow range of sources are routinely cited (Davis 2008; Franklin 1988; Franklin and Van Slyke Turk 1988; O'Neill and O’Connor 2008). This news becomes less local in focus as editions are cut, high-street offices are closed, and use of cheap news agency filler becomes more prevalent (Davies 2008; Franklin 2011; Hamer 2006; Williams and Franklin 2007). This has all led to increasing concerns about the industry's ability to play its democracy-enabling roles.

Harrison, echoing others' findings (Franklin 1988; Franklin and Van Slyke Turk 1988), found that local newspapers reliance on sources in local government means that 'local newspapers are unlikely to be able to perform their role as principal institutions of the public sphere' (Harrison 1998). O’Connor and O’Neill find that local and regional journalists in the North of England rely very heavily on a relatively small range of official sources, usually those with the most resources to devote to media relations (O’Connor and O'Neill 2008). Official sources are quoted the most often, and very few members of the public or local activists were cited at all (491-2). They also note with alarm that the majority of stories (76 per cent) relied on single sources, with less than a quarter of stories employing secondary sources who may provide alternative, opposing, or complementary information to that provided by primary sources (492). This suggests a local press that takes too much information on trust, is too uncritical, and provides readers with limited access to the range of the (often competing) voices and perspectives actually present in local public debates.

Scholars have reached similarly gloomy conclusions about the range of topics covered by UK local newspapers. In-depth coverage of local politics and the governance of local communities has gradually given way to a more tabloid-oriented spread of news (Franklin 2005, Franklin 2006b). Since the mid-1980s the local press in the UK has reduced coverage of local elections, produced fewer election stories with distinct local angles, and a 'growing emphasis on trivial and entertaining coverage rather than a sustained discussion of policy concerns' (Franklin, Court, and Cushion 2006).

The Rise of Hyperlocal Community News 
But the web has enabled a new generation of community-oriented local news outlets, often termed hyperlocal news (Metzgar et al 2011; Kurpius et al 2011). In the USA, as early as 2007, Schaffer produced survey-based research on 500 hyperlocal citizen media sites which found this kind of news outlet to be 'a form of "bridge" media, linking traditional forms of journalism with classic civic participation’ (7). By 2009 distinguished commentators had already accepted that such community news operations had a role to play in sustaining US democracy (Downie and Schudson 2009). Although the market for local news in the USA is still in steep decline, and community news start ups face many challenges around future economic sustainability, there have recently been some signs that smaller local news publishers may be weathering the storm better than some of their mainstream counterparts. The Pew Research Centre recently identified 438 digital organisations that produce original news regularly, most of them local in orientation and found that these smaller, often nonprofit, news sites are the biggest component of a growing US digital news sector (Jurkowitz 2014). Contrasting somewhat with this more mature and established hyperlocal media market hyperlocal community news media are also a part of distinct European national media systems. Fröhlich et al (2012), along with Bruns (2011), have researched the large German community news network MyHeimat. In 2010 Fröhlich's team found a national network of 37,000 citizen journalists collaborating with a number of regional news operations as well as publishing directly to a series of hyperlocal audiences (Fröhlich et al 2012). In the Netherlands, Kerkhoven and Bakker identified 350 hyperlocal news websites publishing in 199 municipalities (Kerkhoven and Bakker 2014). These sites offer diverse, and often very locally-relevant, news, but in common with many community news outlets worldwide, they often struggle to maintain themselves financially.

In the UK hyperlocal community news is less well understood but still attracts sustained interest from the news industry, investors, and policy makers. In their 2012 overview of the emerging network of hyperlocal websites the communications regulator Ofcom claimed that these sites have: 'the potential to support and broaden the range of local media content available to citizens and consumers at a time when traditional local media providers continue to find themselves under financial pressure' (Ofcom 2012, 103). OFCOM data shows that seven per cent of UK adults currently access these sites once a week or more, and 14 per cent at least monthly. By contrast, three years previously Ofcom described the hyperlocal sector as nascent when compared with a stronger US scene.

Many have suggested, often without adequate data to prove, that some of the problems associated with the contraction of mainstream local news publishers can be solved with the advent of online local citizen news. Eulogising about a 'blossoming of hyper-local online ventures' Beckett and Hevre-Azevedo claim that 'hyper-local journalism is not simply a hobby or a pleasant localist addition. It is a potential amelioration of the drastic problem of declining professional regional and local news media' (2010,11). In 2009 the then Labour Government, in its Digital Britain report, cited the 'medium-term potential of online hyperlocal news' to contribute to a gap in the provision 'between the old and new' news media (DCMS 2009, 150). Writing about the US context, Metzgar et al (2011) build on accounts of how the Internet facilitates new forms of news participation, and argue that hyperlocal news can contribute to undermining, but also adding public value to, the kinds of news provision normally offered to communities, specifically in the way they are often intended 'to fill perceived gaps in coverage of an issue or region and to promote civic engagement' (ibid., 774). It is the filling of such real or perceived 'gaps' that concerns Ofcom and other actors who are keen to scrutinise the development of hyperlocal media in light of the decline of commercial local news (Ofcom 2012,103). Our research was designed, in part, to test empirically whether, in what ways, and to what extent, hyperlocal community news can plug the holes left by the retreat of local news from many UK communities. 


\section{Methods:}

We have focussed most of our research on the content of local community news, along with its production. More specifically, we did a large content analysis of UK hyperlocal news, along with an online survey of, and semi-structured interviews with, producers of such news.

\section{Content analysis}

Our sample consists of posts published on the sites of members of the UK's Openly Local news network between the $8^{\text {th }}$ and the $18^{\text {th }}$ May 2012 (Openly Local 2014). Three thousand eight hundred and nineteen posts were published on 313 active websites during this period, and we coded every other story (odd numbers) on each site, a total of 1941 posts (more detailed information about the generation of the sample can be found in Harte 2013a). We coded each story 'live' on the sites in question and did not generate our own archive of this material.

Openly Local does not comprise of a full list of hyperlocal publishers in the UK, and we are aware that many are not included. There is, as yet, no comprehensive list of community journalists in the UK because the sector is so young, informal, and subject to such rapid change. The network is embodied in an openly accessible online map to which local news producers can add their sites should they wish to - it is, in essence, a self-selecting sample. But even with this limitation in mind, we are confident that this large sample allows us the most comprehensive insight yet into the unstable and shifting cultural form of the UK hyperlocal news blog.

In line with our wish to produce findings which are comparable with historical content analyses of mainstream local news in the UK our content analysis pays particular attention, among other things, to: sources (who gets to define hyperlocal news?); topics (what news is covered?); the 'local-ness' of this news; and the civic value of the news (principally, here, in relation to coverage of politics). The detailed content analysis coding frame was drawn up inductively after immersion in the sample.

\section{Interviews}

We conducted thirty six semi-structured interviews with hyperlocal news publishers in the UK. We interviewed producers from a range of different hyperlocal outlets in terms of: the geographic areas served (urban, rural, wealthy, poor, etc); the longevity of the site (some are new, some very long-established); the professional backgrounds of producers (some with varying levels of journalistic training and/or experience, some with none); and approaches to sustaining their operations (some who see their sites as hobbies, some as businesses). Interviews were conducted and recorded over the telephone between October 2013 and May 2014 and later fully transcribed for analysis. They lasted 1 hour and 4 minutes on average, and were designed to gather information about: motivations for doing this kind of work; the day-to-day practice of hyperlocal news work; workloads; relations with audiences; uses of social media; principal challenges faced; and the economic value of hyperlocal news. Here we focus on findings which relate to motivations, sourcing strategies, opinions of and relations with local mainstream media outlets, and discourses about and examples of campaigning, critical, and investigative hyperlocal journalism in order to triangulate our findings with relevant parts of the content analysis. 


\section{Online survey}

The survey data interrogated here focuses principally on the content of community news in order to supplement, contextualize, and explain gaps in knowledge generated from the content analysis. More broadly, our survey was split into sections which covered the running of the site; site reach; site content (split into three categories: information, campaigns and investigations echoing the democratic roles for local news outlined by McNair above); site sustainability and profitability; and economic and human resources expended on community news sites. The range of questions invited single and multiple responses, as well as more expansive qualitative answers in selected cases, principally to elicit examples of practice. This gave us a good quantitative overview in key areas, but also allowed participants to submit longer discursive answers which, in some cases, we subjected to a secondary level of coding and categorization. It was also important that questions were worded so as to gather insights which give us a more longitudinal perspective on the subject matter than the shortterm snapshot of community news our content analysis allowed.

Conducted using online survey tool Survey Monkey, it sampled active sites on the Openly Local network and members of the Talk About Local mailing list (Talk About Local are a hyperlocal advocacy and consultancy group who now manage and update the Openly Local map). ${ }^{i}$ The design and circulation of the survey was a collaboration between our own research team, Steven Barnet and Judith Townend at the AHRC Media Plurality and Power Project at Westminster University, and Will Perrin and Mike Rawlins at Talk About Local. Firstly, an online request was delivered from Talk About Local to 455 members of its email list. Secondly, a more personalised online request was successfully delivered to 216 sites listed on Openly Local, either via email or the contact box on their sites. Finally, we advertised the survey on our blogs and Twitter accounts, which generated 24 additional responses. A total of 183 responses were received altogether (76\% finished the survey). ${ }^{\text {ii }}$ We therefore achieved a response rate of around one third of the original target population (based on Harte's figure of 496 active hyperlocal sites in the UK), making this the most extensive survey of hyperlocal media in the UK to date (Harte 2013b).

\section{Findings and Discussion:}

\section{What gets covered?}

In terms of the topics covered by hyperlocal publishers we found that the largest category of news in the sample related to local community activities (13 per cent). This is, on the whole, a very geographically-focused, community-oriented, journalistic form. This category includes stories about local non-political civil society groups (e.g. the WI, community groups, local clubs \& societies) as well as stories about community events like local festivals. 


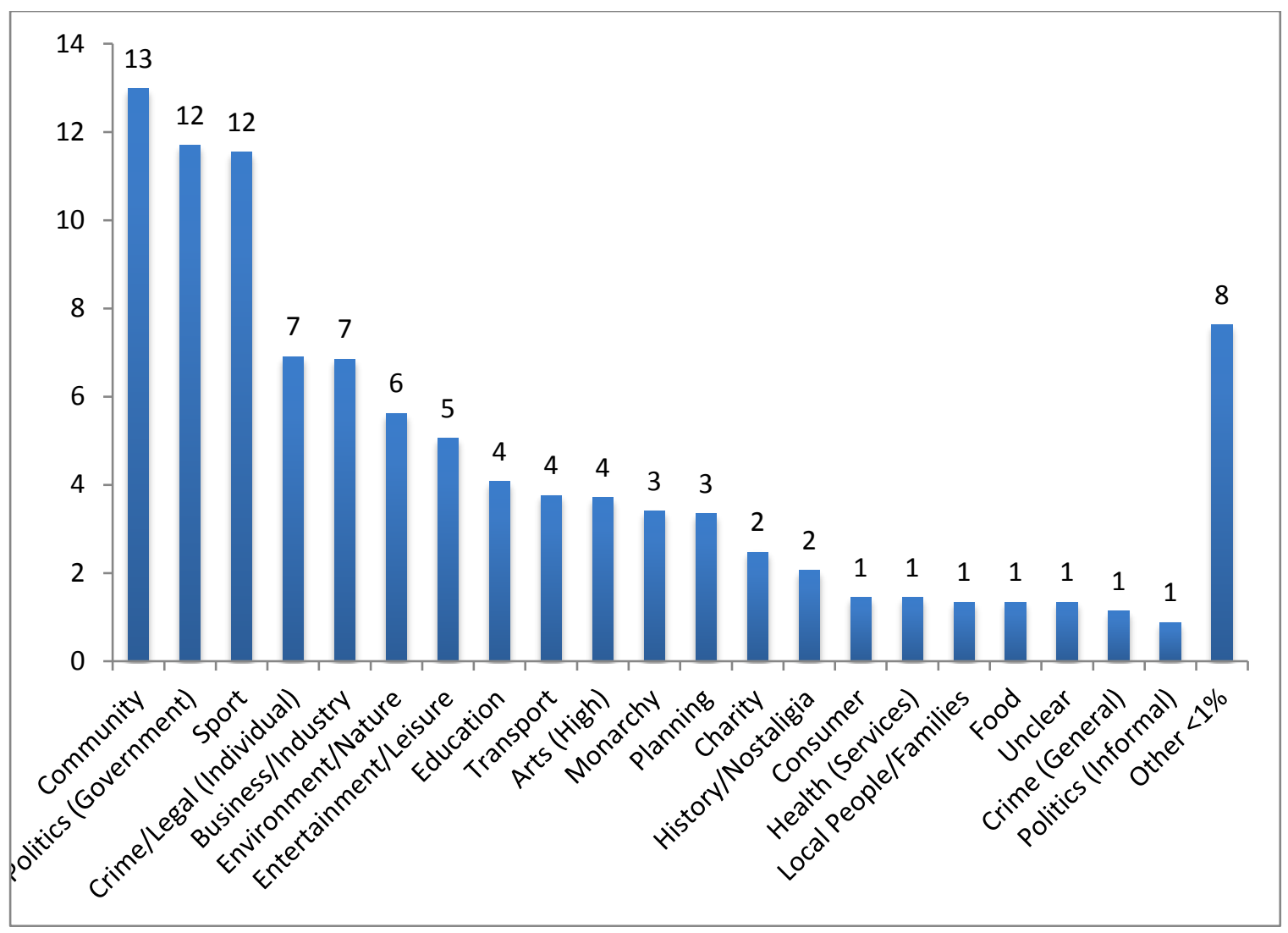

Figure 1: What gets covered? Percentage of topics covered by hyperlocal blog posts $(\mathbf{n}=1941)$

We also found many stories about local councils and the services they provide (11.7 per cent), so we know that hyperlocal audiences are getting a lot of information that in principle could be of civic value. Indeed, this would have been our largest category if we had not separated out stories about local planning (3.3 per cent) which falls under the remit of local government in the UK. This kind of coverage of local politics contrasts somewhat with the UK's mainstream local and regional news media, which has scaled back such coverage in recent years. Other notably large categories included crime and business news entertainment, and the arts.

\section{Putting the 'local' back in local news}

We have seen clearly from the data on story topics that readers of hyperlocal news are getting a large amount of information about politics, particularly the politics of local government, which relates to the news' ability to foster informed citizenship. To investigate this further using content analysis we looked for stories that made any reference to politics and determined whether or not they had an angle that was explicitly locally relevant. Here we generated further indications of the strength of this kind of news when it comes to reporting about local mainstream political spheres. More than a third of stories in our sample make reference to politics (39.1 per cent), and most reference local politics (26.9 per cent). This is encouraging, especially because many of these sites exist in places where depleted local newspapers are operating on skeleton staffs, where they have already been closed down, or where there was never much local news coverage to speak of in the first place. One of the complaints made about the decline of local and regional mainstream news in the UK is that it is becoming increasingly less local in its orientation, at least in part because of the continuing 
cuts to newsroom resources and the increasingly desk-bound nature of local and regional journalism work. This is not a charge which can be levelled at hyperlocal news.

Who gets to speak?

We coded for all directly quoted sources, but also all examples of indirect reported speech.

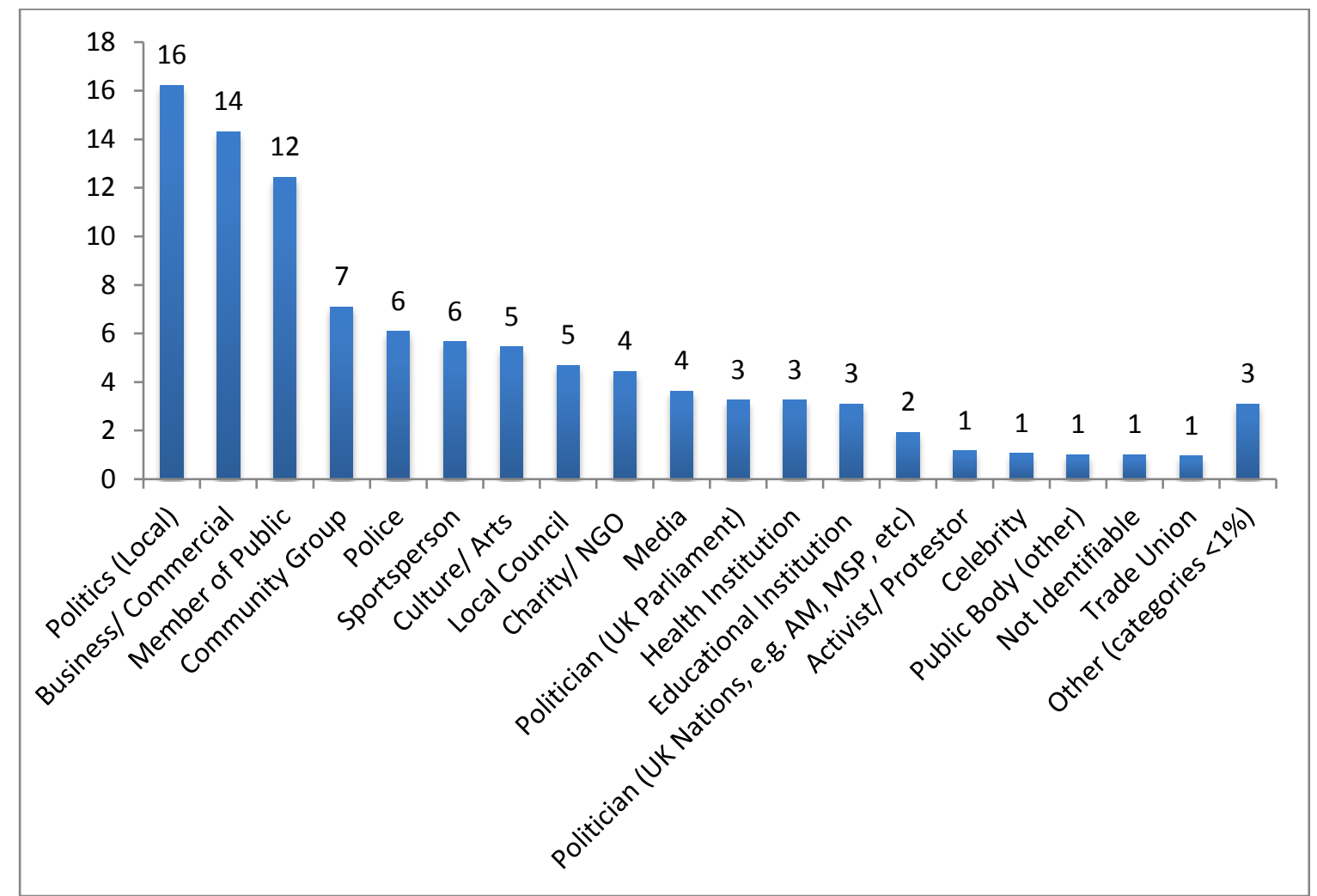

Figure 2: Who gets to speak? Percentage of sources either directly quoted or indirectly cited in UK hyperlocal news $(n=1873)$

When we compare our broad findings on sources with studies of mainstream local news there are some continuities, but also important differences. As in the commercial local news official sources in government, business, and the police are very important: politics at various levels accounts for around a quarter of all sources cited (27 per cent), with business (14 per cent) and the police (6 per cent) also being very influential. But a key difference is the expanded role afforded to members of the general public and to representatives of local civil society groups in this emergent sector (12 per cent and 7 per cent respectively). We expected to find more influence for members of the public actively organised in political struggles or campaigns, but explicitly political activists and trades unionists were thin on the ground in this sample with each group making up just 1 per cent of sources cited.

\section{A plurality of voices?}

The overall number of news sources found in the sample was quite low, and this seems to signal a difference in practice between these emergent community news sites and more established providers of local news. Just over half of posts cited any news sources (56.3 per cent), meaning that many did not contain source input at all. Just as importantly only around a fifth (21.7 per cent) cited more than one source. Studies of traditional news have 
been critical of such under-sourcing, worrying that it leads to a lack of transparency, a lack of plurality in the sources of information to which audiences are exposed, and a lack of opportunity for audiences to learn about conflicting perspectives on particular issues.

We also set out to track the different functions of secondary source intervention, and asked whether each utterance from such sources was: corroboratory (in broad agreement with the primary source); contextual (adding further information to that provided by the firstquoted source); and/or oppositional (expressing disagreement with the first source).

\begin{tabular}{l|l|l} 
& frequency & $\begin{array}{l}\text { Per cent of } \\
\text { whole } \\
\text { sample }\end{array}$ \\
\hline Contextualization & 358 & $18.4 \%$ \\
\hline Corroboration & 304 & $15.7 \%$ \\
\hline Oppositional & 60 & $3.1 \%$
\end{tabular}

Table 1: Functions of secondary source intervention in UK hyperlocal blog posts $(n=421)$

Overall the sourcing of UK hyperlocal news in this sample seems to display a high level of consensus. In terms of the level of debate and the amounts of alternative viewpoints presented on any given story, this journalism, on the evidence of this content sample, seems quite uncritical. Most of the interventions of secondary sources added context and further information to that provided by the first source. Many were in broad agreement with primary sources, giving corroboratory information, however only 3 per cent of all stories in our sample included disagreement between social actors. This further suggests that when it comes to sourcing, audiences are not being exposed to a wide range of alternative viewpoints in relation to the news they read. But the seemingly uncritical nature of the news in this sample, needs to be understood in the context of our interview and survey findings.

Balancing sources is, of course, one of the principal ways in which mainstream professional journalists have performed their commitment to airing a plural range of perspectives on issues of public importance. However, hyperlocal news outlets take a variety of different positions on the issue of providing journalistic balance. Firstly, many hyperlocal news producers have journalistic training and experience, and interview data suggests these are more likely than others to both quote and balance news sources. But we were also told on numerous occasions that not all local news demands the use of multiple, or even single, sources. A key role that many (perhaps even most) hyperlocal sites play is the provision of often quite uncontroversial information about everyday life and activity in their communities. For instance, we found many posts consisted of promotional trails for, or post facto accounts of, events organised by broadly non-political community groups. In the words of one interviewee 'if I'm telling people about a local event I don't need to be getting extra quotes for balance. I don't need to be quoting people.' We also found some evidence that this seeming 'under-sourcing' of individual posts represents a (sometimes unconscious) rejection, or a critique in praxis, of some elements of mainstream journalistic sourcing strategies (Forde 2011, 118-140). For example Daniel Ionescu, the editor of the Lincolnite, told us of an example of a contentious story where he felt his team achieved fair coverage of key differing perspectives by covering competing local points of view in different stories, on different days. 
Others, especially those who produce critical investigative hyperlocal news, take a much less conciliatory stance when it comes to providing space for the perspectives of those they critique. For instance, Quentin Kean of the Leeds Citizen, a retired journalist who describes himself as someone who produces critical news the mainstream local media 'haven't got either the resources or, in some cases, the interest to cover', is clear in his rejection of the need to offer an automatic right to reply in his coverage of local government.

I'm scrupulous that everything I write is always accurate, nobody has ever challenged me about the accuracy of a story I've written. I'm choosing stories that are nearly always about the way interest groups, or political power, works. [But], for example, if I have a story about council stuff, I don't immediately slap off an email to them to the press office for them to give me a quote because they've got plenty of outlets for all of their stuff.

This unwillingness to balance sources in critical reporting is rooted, in part, in a pragmatic expectation that the PR office in question will not take any questions or allegations seriously (Kean talks of 'bland meaningless responses'), but also in a certain amount of contempt for the uncritical way in which local newspapers already routinely provide a mouthpiece for the output of local government communications officers. Mark Baynes, of campaigning London blog Love Wapping, shares these critiques. When asked whether he balances his critical coverage of Tower Hamlets Council with quotes from relevant officers he told us:

I don't see why I should, as a resident, ring the town hall up or anybody else [...]. Because I know all they're going to give me is the usual bullshit. So what's the point? And they've got a huge media machine. [...] I don't see, to be quite honest, why any hyperlocal should. Because if you look at it in the broader context of media and communications in our society: if Tower Hamlets wants to get on TV, they can get on TV. They can send a press release to the East London Advertiser [the local weekly newspaper] [...] and they literally print the press release.

Steven Downes, freelance sports journalist and editor of local investigative site Inside Croydon, elaborated on this, suggesting that the journalistic norm of providing balance through a right to reply sometimes offers council PR offices a way to 'close down' critical reporting by simply refusing to comment. In such cases these hyperlocals have borrowed from the approaches of professional investigative reporting by relying on the quality of their documentary evidence as a way of guaranteeing accuracy and fairness. Referring to balance, and in common with others, Downes told us, 'I've adopted a different attitude. [...] In the end, it comes down to editorial judgement in terms of how you assess a source and the documentation [...] documents are the thing. If you get the document, you're away.'

\section{Hyperlocal campaigning:}

The dearth of non-party political activists and campaigners cited in our content analysis sample initially led us to suspect that campaigns may be under-represented in hyperlocal news. We were wrong, however. Survey and interview data suggest there are two broad ways that hyperlocal news outlets cover campaigns: they actively campaign for change themselves; and/or they cover existing local campaigns. In order to glean a fuller picture of hyperlocal news practice in this area we asked our survey respondents whether they had started campaigns, or covered the campaigns of others in the last two years $(n=159)$. We found that most UK hyperlocals have joined in, supported, or publicised the campaigns (73.3 per cent) 
of others, and a substantial minority (40 per cent) have taken part in their own originallyinstigated campaigning journalism (Barnett and Townend forthcoming). We also asked them how often they undertook such journalism. The average number of campaigns instigated by hyperlocals themselves in the last two years is $3.3(n=55)$, and the average number of campaigns they have 'joined in or supported' was $5.07(\mathrm{n}=81)$. It is clear from the interviews, as well as the more qualitative survey answers, that the subjects of these campaigns vary greatly in size, range, and impact. Some are very local in their focus on issues likely to affect a small number of people, often in quite minor ways, and other issues are more wide-ranging in their effects and more explicitly political in focus.

The raw figures only tell us part of the story. We also asked survey participants to give us a qualitative insight into the campaigns they have run on their community news sites by noting examples of the most recent, and the most important campaigns they have initiated and supported. These qualitative responses were then analysed, categorised, and coded. Campaigns around planning and licensing are both supported and initiated by community news producers, and mainly consisted of planning issues around contentious local developments. Many also included an environmental aspect to do with the protection of local green spaces, or were related to local businesses (e.g. local opposition to the proposed opening of chain supermarket outlets), but a few were about minor local issues such as the granting of alcohol or take-away food licences. Campaigns around local public services (largely in opposition to cuts to such services) were also common in both categories. For instance, there were many campaigns against library closures, and a significant number around perceived threats to the provision of healthcare and education services. Campaigning for improvements to local infrastructure were more commonly supported rather than initiated, either calling on authorities to make - or lobbying against - substantial changes to local roads, train lines, or provision for cyclists. Local business campaigns normally involved calls to promote local independent shops and restaurants, and included numerous 'shop local' campaigns.

Numerous 'community action' campaigns were either in favour of, against, or linked to the activities of local neighbourhood plans and neighbourhood forums, entities enabled under the Localism Act which are designed to enable more democratic control of planning issues. The numerous campaigns against these bodies, however, suggest concern in some communities about how democratic they actually are in practice. Community news producers were quite likely to initiate campaigns which called for improvements to local amenities such as signage, local parks, car parking, play areas, or the cleanliness of a local area (e.g. in relation to those favourite UK hyperlocal preoccupations: litter and dog poo). A number of campaigns dealt specifically with local council responsibilities. Several called for greater transparency and accountability from local government institutions, calling on councils to allow the filming, recording, or live coverage of meetings. It is perhaps unsurprising that these were among the most likely to be initiated by community journalists, as restrictions on reporting directly affect their abilities to cover the affairs of local political institutions. There were also a few instances of much more serious council-related malpractice such as campaigns around the misuse of public funds, or illegal payments made to local businesses.

Hyperlocal coverage of many of these issues, it is claimed, was instrumental in numerous full or partial victories by the campaigners, but even when campaigns were unsuccessful much of this coverage is likely to have led to an enriched local public sphere in the affected communities. There is also evidence to suggest that coverage of campaigns, tapping in as it does, to existing networks of active citizens with an interest in local public life, and covering issues which are of common concern to many, can help hyperlocal producers gain wider audiences, generate social standing, trust and respect from official sources, and become more visible in their communities. 


\section{Hyperlocal accountability reporting: investigations}

Our findings relating to the lack of conflicting perspectives among sources, as well as those which indicate low numbers of non-party grassroots or alternative campaigners, raise the possibility that UK hyperlocal news, on aggregate, may be unlikely to undertake very much critical, accountability, journalism. But a more nuanced and differentiated picture can be obtained when triangulating these research findings with those from the survey and interviews, which allowed us to investigate two broad areas of hyperlocal practice in this regard: investigative hyperlocal news; and non-investigative news which is nonetheless critical of local institutions.

In order to address the issue of investigative hyperlocal news, and to interrogate hyperlocal producers' willingness or ability to carry out this form of watchdog reporting, we asked survey respondents whether they had carried out investigations in order to uncover controversial information of local concern in the last two years. It seems that a substantial proportion of hyperlocal news producers are carrying out investigations. Indeed, around the same proportion (42 per cent), and similar numbers (55), of survey respondents who have started local campaigns also undertake this kind of critical journalistic research (Barnett and Townend forthcoming). As before, respondents were asked for brief details of their most recent, and their most important, investigations.

Examples of investigations survey respondents cited included: environment stories such as a waste incinerator breaching emissions guidelines and plans to develop land poisoned by previous industrial owners; council stories about lack of transparency, or involving (documented) secret or illegal payments; planning issues around supermarket developments, the proposed High Speed 2 railway line, and green field sites being reallocated as brown field in order to allow developments; as well a range of data-led stories about issues as diverse as parking fines, environmental enforcement activities, numbers and rates of crimes solved by local police, use of local libraries in order to argue against cuts to services, and lift failures in council-owned flats.

As well as there being generalist hyperlocals who occasionally carry out investigations, there is a small but influential group of community news sites in the UK who devote themselves almost exclusively to the production of critical and investigative news. Examples include Inside Croydon and Broken Barnett in London, the Leeds Citizen in the North of England, Carmarthenshire Planning Problems and More form rural West Wales, and Real Whitby a seaside town in North Yorkshire. All of these sites have investigated and broken stories of local and national significance, chiefly about political corruption and transparency issues. One might expect, given the demanding, risky, and resource-intensive nature of the research needed to take on local elites that all of these hyperlocal producers would be trained journalists - this is not the case. The most commonly cited methods used in hyperlocal investigations during our interviews are: the careful analysis of public institutional documents and data; Freedom of Information Requests to public bodies (mostly councils) to obtain unpublished documents, data, and correspondence; and leaks and tip-offs (mainly from within local councils, occasionally from private bodies). More risky methods such as undercover work were not encountered.

\section{Hyperlocal accountability reporting: critical news}

In order to explore the production of non-investigative news which nonetheless still includes source input critical of local institutions, or which may take an explicitly critical editorial stance, we asked a series of open questions in the interviews about producers' day- 
to-day practice, how their work relates to the output of other local news producers, as well as their aims and motivations. Many were unequivocal about the need for local news producers to ask awkward questions, to air difficult issues, and hold elites to account. Rachel Howells of the Port Talbot Magnet in South Wales told us 'Somebody's got to be there asking those questions [...] saying, 'well, hang on a minute you've broken the air quality limits three times this month, what's going on?' [...] You've got to have somebody there [to] hold these people to account and have a public forum for that debate.' Howells also told us that the production of such watchdog news can also lead to hyperlocal news outlets being taken more seriously by official sources: 'what we've found to be generally true is that the more firm and journalistic we are, the more critical we are, the more seriously they take us'.

One striking trend in our interview findings, however, does initially seem to lend credence to the suggestion in our content analysis data that this is largely uncritical, and nonprogressive, form of news. There is a very common tendency among hyperlocals to want to portray the place they live in a positive light. Pamela Pinski from the Birmingham blog Digbeth Is Good, for instance, is motivated by 'improving perceptions of Digbeth', a suburb of which she is 'very proud' and for which she is a 'passionate' advocate. Anna Williams, the editor of Northumberland seaside town Amble's fourteen-year-old community newspaper and website the Ambler, similarly speaks of a conscious editorial decision to 'promote the good things that were happening in Amble'. It may be tempting to see this widespread trend as evidence of toothless local news producers who are unlikely to fulfil the critical watchdog function of accountability news. In many cases this would be a mistake. Closer examination of the interview data suggests this tendency is in many cases more accurately interpreted as a reaction to the perceived practice of journalists in the local and regional newspaper industry. It is not just the practice of balancing with which many hyperlocal news producers uncomfortable. When prompted, many define themselves, their working practices, and the news they produce, explicitly against the working routines and news output of mainstream professional local news companies. This is expressed in (sometimes quite vehement) critiques of: local press intrusion; exploitative treatment of community members at the centre of human interest stories; distant coverage which is not reflective enough of community life, is too reliant on press releases, and is too deferential to authority; and coverage which is sensationalist and overly negative. Anna Williams echoes the sentiments of many interviewees: "The only time you ever read anything in the local mainstream press [about Amble] was when some things had been vandalised, or some kids had been nabbed for doing something. It was always doom and gloom.'

Many of those who express a wish to represent their communities to themselves, and to the outside world, in a positive light are also keen to point out that this does not imply they shy away from critical coverage where they feel it is appropriate. Gareth Jenkins, who edits the Kirkbymoorside Town Blog on the edge of the North York Moors in Northern England, for instance, discussed how he was partly motivated to set up the blog to collate information about 'all the things you could get involved in' in the 'buzzy little town' he clearly loves. But this does not, however, mean he is reticent to cover, and facilitate debate about, controversial issues in public life. During our interview he cited numerous examples of news stories which included negative comment and critique including around a controversial housing development, the arrival of a news Tesco supermarket, and divisive and expensive plans to convert a disused library building into new offices for the town council.

\section{Conclusion: the democratic value of hyperlocal news}


In terms of UK community news' ability to (at least partially) plug the ever-widening gaps in UK local and regional news provision we have generated some promising, and some less clearly encouraging, findings. Hyperlocal news, on the whole, is very community- and locally-oriented. By contrast with much professional commercial news, which has become progressively less local in its focus and depth of coverage as resources decline, hyperlocal audiences get lots of locally-sourced stories with strong local news angles. Members of the public and local community groups tend to get more of a say as news sources than in the mainstream local and regional news. Official sources in local government, business, and the emergency services still get a platform, but so do many local citizens. These blogs produce and circulate a lot of news about politics, civic life, local economies, and the business of local government (which is an area of life in the UK that has been under-reported as the crisis in local commercial news has developed).

While some of our findings seem to suggest a rosy picture in terms of hyperlocal news' ability to foster citizenship, democracy, and local community cohesion, others were less unequivocally positive. One of the ways professional journalists provide us with a plurality of perspectives on local life is to speak to numerous news sources to gather the raw materials of news, many of whom they go on to quote in their stories. In our sample, many hyperlocal news producers quote relatively few news sources, and when they are used they rarely provide conflicting or oppositional viewpoints in the same posts. But our interviews suggest that some hyperlocal producers have developed alternative means to foster and inform plural debate around contentious local issues, for example opting to enact source balance by spreading interventions from opposing voices out across different stories. In the case of more overtly critical investigative hyperlocal sites the practice of balancing sources is often rejected on practical and ideological grounds: because council PR departments cannot be relied upon to engage meaningfully with questions, or they use the expectation of being given a right to reply as a tactic to close down debate by stonewalling journalists; because balance is a practice associated with a largely uncritical local mainstream press; and because local elites have enough of a platform for their carefully-crafted communications messages in mainstream commercial news media anyway.

Whilst our content analysis findings seem to suggest a lack of critical, investigative, and campaigning journalism, however, the interviews and survey yielded clear data to the contrary. Many hyperlocal news producers cover the campaigns of others and a significant minority have initiated their own campaigns. Critical investigations are also carried out by a (perhaps surprisingly) large number of UK community journalists on a wide variety of issues of public concern, and a small but effective group of hyperlocal sites devote themselves almost entirely to this kind of public interest news production. There is a strong tendency among many of these sites to want to produce news that paints their local areas in a positive light, but this does not generally mean they shy away from writing critical stories where necessary. Many hyperlocals are, on the contrary, committed to producing news which fulfils the watchdog function of holding local elites to account as well as meeting all of. Indeed, many are also producing news about their local areas that could fulfil many of McNair's above-mentioned commonly accepted social and political roles for journalism. 


\section{References:}

Barnet, Steven, and Judith Townend. 'Plurality, Policy, and the Local: Can hyperlocals fill the gap?’ Journalism Studies (forthcoming).

Beckett, Charlie and Jayme Herve-Azevedo. The Value of Networked Journalism. London School of Economics and Political Science, 2010.

Bruns, Axel. 'Citizen Journalism and Everyday Life: A Case Study of MyHeimat.de.' In Journalists, Sources, and Credibility: New Perspectives edited by Bob Franklin and Matt Carlson. London: Routledge, 2011.

Chambers, Simone and Anne Costain, eds. Deliberation, Democracy, and the Media. London: Rowman and Littlefield, 2001.

Davies, Nick. Flat Earth News. London: Chatto and Windus, 2008.

Davis, Aeron. 'Public Relations in the News.' In Pulling Newspapers Apart; Analysing Print Journalism edited by Bob Franklin. London: Routledge, 2008.

Department for Culture, Media and Sport (DCMS). Digital Britain. HMSO. 2009.

Downie, Leonard, and Michael Schudson. (2009) The Reconstruction of American Journalism. New York, NY: Columbia University Publications

Fenton, Ben. 'Bad Ad News Ripples Across the Sector.' Financial Times $1^{\text {st }}$ July 2008.

Fenton, Natalie. 'Deregulation or Democracy: New Media, news, neoliberalism and the public interest.' Continuum: Journal of Media and Cultural Studies 25, no.1 (2011): 63-72.

Franklin, Bob. Public Relations Activities In Local Government. London: Charles Knight, 1988.

Franklin, Bob. 'McJournalism: The Local Press and the McDonaldization Thesis.' In Journalism: Critical Essays edited by Stuart Allen. Milton Keynes: Open University Press, 2005.

Franklin, Bob. 'Preface.' In Local Journalism and Local Media: Making the local news edited by Bob Franklin. London: Routledge, 2006a.

Franklin, Bob. 'Attacking the Devil? Local Journalists and Local Papers in the UK.' In Local Journalism and Local Media: making the local news edited by Bob Franklin. London: Routledge, 2006b.

Franklin, Bob. 'Sources, Credibility, and the Continuing Crisis of UK Journalism.' In Journalism, Sources, and Credibility edited by Bob Franklin and Matt Carlson. London: Routledge, 2011.

Franklin, Bob, and Matt Carlson. 'Introduction.' In, Journalism, Sources, and Credibility edited by Bob Franklin and Matt Carlson. London: Routledge, 2011. 
Franklin, Bob, Geoff Court, and Stephen Cushion. 'Downgrading the 'Local' in Local Newspapers' Reporting of the 2005 UK General Election.' In Local Journalism and Local Media: Making the local news edited by Bob Franklin. London: Routledge, 2006.

Franklin, Bob, and Judy Van Slyke Turk. 'Information Subsidies: Agenda setting traditions.' Public Relations Review Spring (1988): 29-41.

Fröhlich, Romy, Oliver Quirling, and Sven Engesser. 'Between Idiosyncratic Self Interest and Professional Standards.’ Journalism 13, no.8 (2012): 1041-63.

Habermas, Juergen. The Structural Transformation of the Public Sphere: An Inquiry into a Category of Bourgeois Society. Cambridge (MA): MIT Press, 1989.

Hamer, Martin. (2008) 'Trading on Trust: News agencies, local journalism, and local media.' In Local Journalism and Local Media: Making the Local News edited by Bob Franklin. London: Routledge, 2008.

Harrison, Shirley. 'The Local Government Agenda: News From the Town Hall.' In Making the Local News: Local Journalism in Context edited by bob Franklin and David Murphy. London: Routledge. 1998.

Harte, Dave. 'One Every Two Minutes: Assessing the scale of hyperlocal publishing in the UK.’ JOMEC Journal 1, no.3 (2013a).

Harte, Dave. 'Hyperlocal Publishing in the UK - A 2013 Snapshot.' 11 October 2013b, available at: http://daveharte.com/hyperlocal/hyperlocal-publishing-in-the-uk-a-2013snapshot/ (last accessed July 2014).

Hartley, John. The Uses of Digital Literacy. New Brunswick: Transaction, 2009.

Jurkowitz, Mark. 'The Growth in Digital Reporting.' Pew Journalism Research Project, March 26 2014, available at: http://www.journalism.org/2014/03/26/the-growth-in-digitalreporting/ (last accessed July 2014).

Kerkhoven, Marco, and Piet Bakker. 'The Hyperlocal in Practice: Innovation, creativity, and diversity.’ Digital Journalism (Forthcoming).

Kurpius, David, Emily Metzgar, and Karen Rowley. 'Sustaining Hyperlocal Media: In search of funding models.’ Journalism Studies 11, no.3, (2010): 359-376.

McNair, Brian. 'Journalism and Democracy.' In The Handbook of Journalism Studies edited by Karin Wahl Jorgensen and Thomas Hanitsch. New York and London: Routledge, 2009.

Metzgar, Emily, David Kurpius, \& Karen Rowley. 'Defining hyperlocal media: Proposing a framework for discussion.’ New Media \& Society 13, no.5, (2011): 772-87.

Ofcom. Local and Regional Media in the UK. London: Ofcom, 2009.

Ofcom. The Communications Market Report: United Kingdom. London: Ofcom, 2012. 
O’Neill, Deidre and Catherine O’Connor. 'The Passive Journalist; How Sources Dominate Local News.’ Journalism Practice 2, no.3 (2008): 487-500.

Openly Local. 'Hyperlocal Sites in UK and Ireland.' London: Openly Local, 2014, available at: http://openlylocal.com/hyperlocal_sites (last accessed July 2014)

Radcliffe, Damian. Here and Now: UK hyperlocal media today. London: Nesta, 2012

Schaffer, Jan. Citizen Media: Fad or The Future of News? The Rise and Prospects of Hyperlocal Journalism. 2007, available at: http://www.j-

lab.org/_uploads/downloads/citizen_media-1.pdf (last accessed July 2014)

Taggart, Chris. 'Yet another UK Hyperlocal Directory... but this time it's open data.' CounterCulture 13 January 2010, available

at: http://countculture.wordpress.com/2010/01/13/yet-another-uk-hyperlocal-directory-butthis-time-its-open-data/ (last accessed July 2014)

Thurman, Neil, Jean Christophe Pascal, and Paul Bradshaw. 'Can Big Media Do Big Society? A Critical Case Study of Commercial, Convergent Hyperlocal News.' International Journal of Media and Cultural Politics 8, no.2 (2012): 269-85.

Williams, Andy and Bob Franklin. Turning Around the Tanker: Implementing Trinity Mirror's Online Strategy. Cardiff University School of Journalism Media and Cultural Studies, 2007, available at: http://image.guardian.co.uk/sysfiles/Media/documents/2007/03/13/Cardiff.Trinity.pdf (last accessed July 2014)

\footnotetext{
i 'Active' was defined as 'a website having posted a news story at least once in the 5 months prior to the sample period'. Inactive sites had either closed, or had not published in the 5 months prior to his sampling (Harte 2013b).

ii The response rate was higher from the list compiled from the Openly Local directory (86 of 216: 39.8\%) than from the Talk About Local mailing list (69 of 455: 15.2\%). There are two main reasons that could explain the low response to the TalkAboutLocal mailing list. Firstly, the request for participation took the form of a generic newsletter (only 115 of 455 recipients opened the email); and secondly, the mailing list contained contact details for people who were interested in hyperlocal media, but do not publish sites themselves.
} 